Cohen Scott (Orcid ID: 0000-0003-1260-8577)

\title{
Gender discourses in academic mobility
}

Prof Scott Cohen ${ }^{\mathrm{a}}$

s.cohen@surrey.ac.uk

(1)

Dr Paul Hanna ${ }^{\mathrm{a}}$

Prof James Higham ${ }^{b, c}$

Dr Debbie Hopkins ${ }^{\mathrm{d}}$

Dr Caroline Orchiston

${ }^{a}$ Faculty of Arts and Social Sciences, University of Surrey, Guildford, GU2 7XH, United Kingdom

b Department of Tourism, University of Otago, PO Box 56, Dunedin, 9054, New Zealand

${ }^{c}$ Norwegian Hotel College, University of Stavanger, Norway

d School of Geography and the Environment, University Oxford, South Parks Road, Oxford, OX1 3QY, United Kingdom

${ }^{\text {e }}$ Centre for Sustainability, University of Otago, PO Box 56, Dunedin, 9054, New Zealand

There are no conflicts of interest in the submission of this paper.

\footnotetext{
This article has been accepted for publication and undergone full peer review but has not been through the copyediting, typesetting, pagination and proofreading process which may lead to differences between this version and the Version of Record. Please cite this article as doi: 10.1111/gwao.12413
}

This article is protected by copyright. All rights reserved. 


\section{Abstract}

Despite increasing geographic mobility among academic staff, gendered patterns of involvement in academic mobility have largely escaped scrutiny. Positioned within literatures on internationalisation, physical proximity, gender and parenthood in academic mobility and understandings of gender as a process enacted through both discursive and embodied practices, we use discourse analysis based on interviews with academics in New Zealand to examine differences in language that create differing realities with regards to gender and obligations of care in academic mobility decisions. The findings reveal how academic mobility is discursively formulated as 'essential' to successful academic careers, with the need for frequent travel justified despite advances in virtual communication technologies. Heteronormative discourses are shown to disrupt and fragment the opportunities female academics have to engage in academic mobility. However, we also uncover ways in which these discourses are resisted, wherein fathers articulate emotional strain associated with academic mobility. The paper shows how discourse works to constitute the essentialisation of academic mobility, and the uneven gendered practices associated with it, whilst also giving voice to gender inequities in academic mobility from the southern hemisphere.

Keywords: academic travel, gender, parenthood, discourse analysis, New Zealand 


\section{Introduction}

University academic staff are part of a wider transition from industrial to knowledge societies, wherein 'an increasing proportion of the population is engaged in developing, using and communicating scientific or expert knowledge' (Høyer \& Naess, 2001, 451). Employees of knowledge industries, like consultants and managers, are part of a highly skilled workforce that is the most mobile segment of the population globally (Bergström Casinowsky, 2013; Lassen, Laugen \& Naess, 2006; Schiller \& Diez, 2012). Academic careers have a longstanding association with high levels of corporeal mobility (Parker \& Weik, 2014), and this has in the past been implicitly associated with living abroad for a period of time (Ackers, 2008). In this article a broader temporal understanding of the geographic mobility of academic staff is taken, ranging from longer-term advanced training, periods of sabbatical leave, research fieldwork or visiting researcher positions to shorter-term travel for conferences, courses and other meetings (Fontes Videira \& Calapez, 2013; Hopkins, Higham, Tapp \& Duncan, 2016; Parker \& Weik, 2014). This is in the context of increasing recognition that 'academics have led [the] way on the now-popular business trend towards international assignments', and are progressively more obliged to be mobile in a variety of ways (Baruch \& Hall, 2004, 254; Høyer \& Naess, 2001; Storme, Faulconbridge, Beaverstock, Derudder \& Witlox, 2017; Hopkins, Higham, Orchiston \& Duncan, 2019).

The ongoing internationalisation of academia, as part of processes of globalisation and the neoliberalisation of universities, has amplified the demand for academics to have international contacts (Høyer \& Naess, 2001). International mobility plays a 'signalling role in the scientific labour market' and has 'become an intrinsic element of a scientific career' throughout all academic fields (Fontes et al., 2013, 440). It is expected to allow researchers to build 
international scientific networks, which can lead to benefits for both mobile academics and the universities who employ them (Fontes et al., 2013). International collaboration has become a central requirement in academic promotion and career success, with 'many universities pushing for global connectedness and collaboration as a performance norm across disciplines' (Glover, Strengers \& Lewis, 2017, 2), to the point where transnational academic mobility has become an 'expectation' within careers (Ackers, 2008; Leemann, 2010). Academic staff, and in particular early career researchers, who choose to reduce or restrict travel may perceive themselves at a career disadvantage (Hopkins et al., 2016; Lassen, 2009).

Air travel is an important enabler in international work-related travel for coping with obligations to networks (Lassen, 2009). Yet critics of academic mobility have unveiled it as 'an exercise in privilege', which through its reliance on carbon-intensive air travel contributes a large 'professional ecological footprint' (Nevins, 2014, 306). Further studies of the social inequalities of academic mobility have also focused on its associated environmental injustices (Glover et al., 2017; Hopkins et al., 2016), and have analysed university policies on internationalisation and mobility to understand how these construct frequent air travel practices amongst academic staff. This paper is also concerned with issues of social justice in relation to academic mobility, but takes a different point of departure in its focus on discourses of gender. Gender inequities persist in academic careers (Bailyn, 2003; Windslow \& Davis, 2016), and it has been observed that caring commitments can suppress academic travel (Hopkins et al., 2016; 2019). Indeed, Windslow and Davis $(2016,408)$ suggested that 'gender is institutionalized in academic careers in ways that disproportionately hinder females with children, even as policies have emerged to address the immediate demands of childbearing and caretaking needs', and they find that the requirement(s) of academic mobility can be contributory factors. 
Though there is a rich body of work on gender dimensions in relation to work-related travel (e.g. Bergström Casinowsky, 2013; Gustafson, 2006), less is known about gender relations in academic mobility practices (Jöns, 2011). Some important exceptions to this include Leeman's (2010) study of how gender affects decisions to work abroad for Swiss postdoctoral researchers; Jöns' (2011) longitudinal analysis of gender in the transnational and mostly circular mobilities of German academics; and Jöns' (2017) historical examination of academic travel within the careers of early female academics at the University of Cambridge. Scholars have consequently recently called for further research on gendered patterns of involvement in academic mobility, which aims to 'achieve a better understanding of gender inequalities without stereotyping gender differences' (Jöns, 2017, 679; Storme, et al., 2017).

This paper responds to these calls through a discourse analysis based on interviews with academic staff at the University of Otago in New Zealand on their academic mobility practices. Our aim is to examine the subtle differences in language that create differing realities with regards to gender and obligations of care in academic mobility decisions. Gender is understood in this paper as constructed, performed and resisted; a process enacted via discursive and embodied practices (Heyes, 2007). Our empirical focus on differences in language use, or discourse, has the potential to contribute a new theoretical understanding of how academic mobility is discursively constructed as an essential element to academic life, with gendered consequences. The paper furthermore contributes to a body of work on gender that seeks to avoid the perpetuation of discursive binaries, through challenging heteronormative discourses, and also provides an empirical focus on gender dimensions in academic mobility that takes account of geographical considerations from within the southern hemisphere. This is important as the focus of key past studies on gender in work- and academic-related mobility has been in Europe (Bergström Casinowsky, 2013; Gustafson, 2006; Jöns, 2011; 2017; Lassen, 2009; Leemann, 2010; Santos, 2015). The paper is first theoretically framed within the existing 
literature on internationalisation, physical proximity, gender and parenthood in academic mobility and understandings of gender as a process enacted through both discursive and embodied practices (e.g. Heyes, 2007), before turning to its empirical focus.

\section{Internationalisation and physical proximity in academic mobility}

Mobility has increasingly become a proxy for internationalisation, excellence and competitiveness, though this reciprocal link is beginning to be questioned (Ackers, 2008; Leemann, 2010). Researchers are considered 'carriers of unique knowledge resources', with much of this knowledge tacit and non-codifiable, and thus only transferable through situations in which 'people work together closely, are able to observe each other's actions and can calibrate their communication' (Schiller \& Diez, 2012, 132). Within academic mobility the most effective transfer of tacit knowledge has commonly been associated with migration, though the mobilities of highly skilled migrants are becoming increasingly temporary and circular (Saxenian, 2005). This development is reflective of the rise of short 'shuttle stays' in academic mobility patterns, in which the success of collaborative work has become less dependent on very long stays (Ackers, 2008).

The importance of tacit knowledge transfer, and its spill-over effects, alongside the recognised benefits of collaborative networks, have informed internationalisation strategies in universities. Academic mobility has become institutionalised, whereby it is encouraged and audited by universities (Parker \& Weik, 2014). Universities now socialise students into academic mobility and compel academic staff to travel, from study abroad programmes and work placements to invited keynotes and adjunct appointments (Hopkins et al., 2016). Fontes et al. (2013) discuss the importance of temporary physical proximity between individuals in creating social and cognitive relationships that may facilitate knowledge transmission and network building, and 
point out how the links that develop can persist when individuals draw apart, though further instances of physical proximity may be needed to avoid relationship decay.

It was often argued that advances in information and communication technologies allow for virtual communication to be substituted for face-to-face interaction (Lassen et al. 2006; Higham, Hopkins \& Orchiston, 2019). However, the weight of evidence in recent studies suggests that despite the availability of videoconferencing, and other ways of communicating remotely in real-time, face-to-face proximity, facilitated primarily by air travel, remains the dominant form of meeting in the internationalised workplace (Glover et al., 2017; Strengers, 2015). Storme et al. $(2017,420)$ have shown that virtual presence has not become a substitute for physical proximity within the demands of academic mobility, but instead the two forms are juggled to meet 'conflicting obligations of presence'.

Lassen et al. (2006) conclude that networking through virtual communication systems is difficult, and that face-to-face meetings are crucial to establishing confidence and trust. Physical proximity is viewed as particularly important in informal work relations, with 'networking in the corridor or informal meetings over a cup of coffee assuming great importance' (Lassen, 2009, 233), as is certainly the case at academic conferences and meetings, where informal conversations on the margins of events may be more important than the formal proceedings. Strengers $(2015,606)$ has shown the importance of the body in the informal moments of physical co-presence that Urry (2003) has referred to as 'meetingness', in suggesting that 'telepresence remains unable to reproduce the sensorial competency enabled through the physical co-presence of the body'.

In summary, institutionalised conflation of excellence with geographic mobility and the socially perceived importance of 'meetingness' in developing and maintaining relationships goes some way in answering Parker and Weik's (2014) curiosity as to why despite there being 
no 'obvious technical reason why super-mobility is necessary to do the research work of an academic', virtual communication has not eradicated the need for physical proximity. Studies now largely agree that rather than substituting for face-to-face travel, virtual communication complements and combines with instances of physical proximity, and that this is fuelling global growth in geographically dispersed social connections (Agueliera, 2008; Strengers, 2015). A consequence of this is the ongoing expansion of work-related travel needed to maintain these relations. Academic mobility is no exception to this paradox.

\section{Gender and parenthood in academic mobility decisions}

Given both the embedded institutional expectation of shorter- and longer-term spatial mobilities in academic careers (Ackers, 2008; Leemann, 2010; Parker \& Weik, 2014) it is problematic to consider academic mobility as an individual choice. Academic mobility decisions, not unlike King's (2002) argument in the context of migration, lie along a complex and blurring spectrum between coercion and free-will. Though academic staff will typically have a higher degree of self-determination in their mobility choices than employees in other knowledge industries, as for example in the corporate environment (Cohen, Hanna \& Gössling, 2017; Lassen, 2009), the institutional drivers for academic career success act as powerful motivations to travel.

Work-related mobility is often adapted based on family situation (Gustafson, 2006), yet the gendered division of domestic responsibility is a 'relatively overlooked' dimension of workrelated travel (Bergström Casinowsky, 2013, 312). Research in Sweden has shown that having young children reduces work-related travel among female workers far more so than for male workers (Gustafson, 2006). Bergström Casinowsky (2013) concludes that whereas male workers reduce their relative share of home-based responsibility when travelling frequently for 
work, the allocation for female workers in the same situation is unaffected. She argues that this double burden may be explained by the perception that overnight travel for work may be perceived as an 'offence against conventional norms of womanhood, calling for some kind of compensatory action' such as 'sustaining the same level of responsibility at home regardless of having less time available to do so’' (Bergström Casinowsky, 2013, 323).

Not unlike work-related travel more generally, the most obvious consequence of the increasing demand for academic mobility is on the gender politics of caring (Parker \& Weik, 2014). Past studies have tended to consider academic mobility in terms of what Leemann $(2010,613)$ refers to as 'an individualistic male breadwinner model', without giving due consideration to gender, partnership and family dynamics. Parenthood has been shown to have unequal effects between female and male academics in career progression and in employment stability: male academics benefit more as they are less affected by the constraints of parenthood (Santos, 2015). This is at least partly explained by more female than male academics reporting changes to their career aspirations, and as also found in Bergström Casinowsky's (2013) study of work-related travel more widely, female academics doing more childcare and domestic work concurrently with their academic career (Santos, 2015).

Leemann (2010) argues that family status is an important determinant of academic mobility patterns. Academics are known to postpone mobility obligations during certain life phases, particularly when caring obligations are high (Storme et al., 2017). In contrast, researchers 'who engage in calculated, repeated international mobility in order to invest in their human and social capital...typically involve people who have relatively limited personal (or caring) responsibilities' (Ackers, 2008, 415-416). Ackers (2008) suggests that the completion of doctoral degrees often falls at a time in individual's lives when partnerships are established and/or families are started, and that caring obligations for children, among other reasons, often delays or restricts longer-term academic mobility. She questions the compatibility of mobility 
with concerns over achieving work-life balance and concludes that 'not all researchers are equally footloose and that requiring mobility may give rise to discriminatory outcomes' (Ackers, 2008, 430). Parker and Weik $(2014,177)$ concur in suggesting that “...the dice seems to be loaded against professional academics with attachments".

Historical study of the academic travel of early female researchers at the University of Cambridge has shown that although female researchers took academic leave as frequently as male researchers, they travelled far less overseas and rarely attended conferences (Jöns, 2017). Such gendered differences persist, as recently argued by Santos $(2015,4)$ : 'many academic women have more difficulties than most men fulfilling the requirements of an academic career model...characterized by the need to spend long hours in research activities or frequent travelling and long absences away from home'. This is also evidenced in Lassen's (2009) comparative study of knowledge workers in Denmark from academia and industry, which suggests that male workers travel for work considerably more than female workers, younger employees without partners or children travel the most and single parents travel the least. This led Lassen $(2009,239)$ to conclude that 'the family factor seems to be the most important brake on mobility'.

Leemann (2010) studied the dynamics of gender and other structural factors as they relate to longer periods of work abroad of Swiss researchers during the postdoctoral phase, and likewise found that both the birth of children and a stable partnership make these mobility decisions less likely. A focus on longer-term research stays is also found in Jöns' (2011) study of visiting researchers at German universities. These stays are found to be for the most part circular, in that most visitors return to their country of origin after one or two years, but also highly differentiated by gender, in that female academics are under-represented as visiting researchers, particularly within the natural sciences. A further key finding is how these gender differences relate to the life course, with Jöns $(2011,205)$ also showing that international relocation drops 
off significantly for female researchers beyond the average age of 35 , with this mobility constraint attributed to "prevailing traditional family patterns and gender roles in which domestic work, including the care for children and the elderly, predominantly resides on the shoulders of women'.

Parenting as a gendered practice also has both geographical and cultural nuances. For instance in a study of Portuguese academics, Santos (2015) found a group she terms 'family-oriented academics', who tend to have young children and put limits on travelling for work. Within this group are male academics who identify stronger with fathering than being an academic, and thus challenge hegemonic representations of masculinity as uninvolved with caregiving. Like Santos (2015) and Jöns (2017), our goal in this paper is not to stereotype the life course trajectories of female or male academics with regards to academic mobility, and thereby reproduce a heteronormative binary discourse. We instead focus on how binary understandings of gender roles, parenting and family obligations in relation to academic mobility are discursively formulated, as well as how such a split is challenged and resisted. To offer such a position we shall now build on this notion of discursively formulated concepts by providing a brief account of the theoretical underpinnings of this paper to give the reader an insight in to the ways in which we conceptualised gender.

Gender as a concept is heavily contested (Edley \& Wetherell, 2008). Whilst essentialised understandings of gender conflate the concept with biological sex, we recognise and agree with the critiques of gender as an essential sex category as it fails to acknowledge the complexity of the psychological, social, historical and political spheres that formulate subjectivities (Bohan, 1993). Therefore, for the purpose of this paper, we conceptualise gender as constructed, performed, embodied and resisted (Heyes, 2007). Gender is therefore not seen as an essential concept but rather as a process of gendering enacted through language and embodied practices. 
Given our analytical approach of Foucauldian Discourse Analysis (FDA), we turn to the reading and application of Foucault from Heyes (2007) in which she challenges the individualistic neoliberal ideology in which each individual is equal and can pursue their own ends. Heyes (2007) suggests that this ideology, coupled with liberal discourses of equal opportunities, has recreated and reinforced sexist discourses whilst also making them almost transparent. However, rather than just exposing how these discourses construct subject positions and subjectivities, Heyes (2006) suggests that researchers should embrace the possibility that individuals have some capacity to reflect on the dominant power/knowledge structures that attempt to constrain and construct by focusing on both moments of construction, alongside moments of resistance (Hanna, 2013). Heyes (2007) argues that whilst this process of reflection is fraught with negotiation and struggle, it is through an understanding of how individuals are 'living in the fissures' that we are able to better explore the ways in which individuals can 'experiment with subjectivity' (Hanna, 2013), in this instance, gendered subjectivities. This theoretical understanding of gender as processual and enacted through both discursive and embodied practices provides a basis and justification for this paper's method of analysis, FDA, which is detailed in the following section.

\section{Methodology}

\section{Our data}

This paper draws on a series of one-to-one semi-structured interviews conducted with academic staff at the University of Otago as part of a wider project on academic mobility. The university is in Dunedin, on New Zealand's lower South Island, and is dependent on air travel for most inter-city business travel. Although Dunedin has a nearby international airport, most long-haul flights require a connecting flight to/from Christchurch or Auckland. Universities in New 
Zealand, as a result of the country's physical remoteness, 'have historically prioritised academic mobility to remain internationally competitive ... and connected' (Hopkins et al., 2016, 378). Semi-structured one-on-one interviews were used in order to provide an in-depth account of academic staff understandings of academic mobility.

Our programme of interviews was guided by an interview schedule that explored professional practices, institutional expectations and personal circumstances in relation to academic mobility practices. The semi-structured nature of interviews accommodated our wish to explore avenues of discussion that were important to the research participants, regardless of whether or not they were identified as important in the planning of the research (Jennings, 2001). In conducting two-way conversational interviews, insights were generated that were co-created and mutually informative. The gendered consequences of academic mobility clearly emerged as an important avenue of discussion during the course of the interview programme.

To achieve a university-wide sample of academic staff and minimise self-selection bias, all departments within the University of Otago that met a minimum number of academic staff were listed and selected using the Excel random number function, while ensuring at least three departments from each of the university's four academic divisions were included. Using the same random number function, individual academic staff from each selected department were chosen. Conflicts of interest were carefully considered by the researchers, given that study participants were also institutional colleagues. All colleagues with whom any member of the research team had a close professional or personal connection were removed. The sample was then stratified to ensure coverage of the academic scale and gender representation. As necessary, female academics were purposively sampled by randomly generated numbers from a list that included only the female academic staff of a department. The research was conducted in accordance with the required institutional ethical approval. Interviewees were informed in advance that participation in the study was voluntary, and that they were free to withdraw at 
any time without disadvantage. The open-ended nature of the interview questions was explained, as was the option to decline to answer questions if the line of discussion caused any sense of hesitancy or unease. The recruitment of study participants from multiple departments within each of the four divisions ensured the anonymity of interviewees. All interviewees agreed to be interviewed and signed a consent form prior to interviews being conducted.

In total 31 interviews were conducted (see Table 1): seven from Business departments (Economics, Accountancy \& Finance and Marketing), eight from Humanities departments (Music, Classics and Philosophy), eight from Sciences departments (Chemistry, Physics, Surveying, Zoology, and Physical Education, Sport and Exercise Sciences) and eight from Health Science departments (Microbiology, Obstetrics \& Gynaecology and Anatomy). Participants included 21 male and 10 female staff, and a balance of academic positions (Professors 8; Associate Professors 8; Senior Lecturers 7; Lecturers 5; Senior Research Fellows 2; Postdoctoral Fellows 1). Although significant effort was made during interviewee recruitment to achieve gender balance, getting female academics to participate proved difficult. Interviews ranged in duration from 22-59 minutes with a total duration of 1317 minutes (21 hours, 57 minutes) and an average of 43 minutes per interview. While there is no 'perfect' sample size in qualitative research, at the time of the interviews the research team felt this sufficiently reflected a broad range of opinions and demographic characteristics. All interviews were digitally recorded with the written consent of participants, and fully transcribed verbatim. These are referenced by an interview code convention that includes interview number (\#), academic division (Com/HS/Hum/Sci), gender (M/F) and level of appointment (junior/senior).

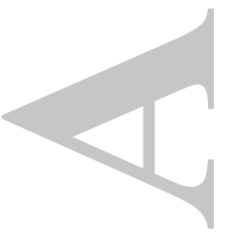




\section{Method of analysis}

In general terms discourse analysis provides a 'tool' to de-construct language, identifying a variety of 'terms' or 'phrases' in order to examine the production and negotiation of meanings (Clarke \& Saraga, 2003). Discourse analysis allows for the examination of the subtle differences in language that create particular versions of reality in specific situations. This enables the researcher to relate what is said and what is not said to the particular setting in order to establish a deeper, more critical view of why discourse is delivered and perhaps more crucially, what it achieves (Bhavnani \& Phoenix, 1994). FDA (e.g. Parker, 1992) calls for consideration of the ways in which the power/knowledge nexus functions to achieve certain subject positions, subjectivities and ways of being. Therefore, this approach seemed particularly relevant for this research as it enables an appreciation for the ways in which language and discourses offer up and close down particular 'ways of being' (Rose, 1989). When considering academic mobility and gender this seems to be of particular importance as there is no formal contract that requires academics to engage in travel practices, rather notions of academic [im]mobility and their implications are more subtly constructed, created and recreated through ways of talking and 'common sense' assumptions (Potter \& Wetherell, 1987). To undertake FDA a number of researchers have suggested a series of 'steps' to provide coherence in the process (Parker, 1992; Willig, 2001; 2008). Willig's (2013) six-stage FDA process was selected as an appropriate method of analysis for this research as it has been deemed to sufficiently condense Parker's (1992) original 20 stages into six without compromising its analytic strength (Hanna, 2014). In addition to the six stages set out by Willig (2013), our analysis paid attention to the moments of resistance and understandings of embodied experiences within the participants accounts (Hanna, 2014). The following section documents the way in which the analytic process was applied to our data. 
The first stage to the analytic process involved identifying the ways in which discursive objects were constructed. In relation to this study the research focus was specifically on how objects such as 'mobility', 'academia', 'academic' and 'gender' were constructed throughout the data set. All references (implicit and explicit) to these objects were coded. For example, was the object 'gender' explicitly referred to, and if not, was it constructed through a range of metaphors and/or practices? The next stage of the analysis was to explore how these objects are constructed in multiple ways through competing discourses. For example, is 'gender' as an object presented though a heteronormative discourse in which male and female academics are presented as 'naturally' different in terms of traits such as 'drive', 'dominance' and 'caring'? What could be an alternative discourse through which this object could be constructed? Through an examination of the different ways in which the same object was constructed it was possible to start to see how different discourses were drawn upon to facilitate and negotiate these alternative and, often contradictory, constructions of the same object.

The third stage of the analysis involved an examination of the 'action orientation' establishing how objects relate to each other. Questions were asked of the text, such as 'what is gained from constructing the object in this way in this context'? For example, how is 'mobility' presented as a positive or negative and what does this achieve for academic mobility? The fourth stage suggested by Willig (2013) is concerned with the subject positions these broader discourses offer. This stage of the research was concerned with how multiple 'types' of 'male academic' and 'female academic' are constructed and positioned in relation to academic mobility through the discourses utilised in the participants' talk. This allowed the analysis to examine the ways 'subjects' are positioned in relation to one another and how power can circulate through these positions. Alongside the subject positions offered throughout the data, the analysis was concerned with how particular positions encourage and constrain subjectivities or ways of being. For example, what practices and behaviours are constructed as legitimate 'ways of 
being' for male and female academics? Finally, the relationship between the objects, discourses, action orientation, subject position, and subjectivity were examined to highlight the potential implications for the actors involved. This section is inherently speculative but it seeks to suggest '.... what can be felt, thought and experienced from within various subject positions' (Willig, 2013, 136). This aspect of the analysis enabled us to speculate on the implications of positioning the subjects within particular discourses. For example, what are the implications of this on career opportunities and individual pressure, stress and wellbeing?

\section{Findings and discussion}

Due to the differing degrees of familiarity with the data between the author and the reader, and the subjective nature of qualitative analysis, the presentation of qualitative findings in publications is always a difficult balance (Willig, 2013). In this section we organize our findings in two main sections, with two subsections in each, and in line with critical qualitative analysis our findings are discussed in relation to extant theory and literature throughout. The first section examines how academic mobility is discursively formulated as 'essential' to successful academic careers. It does so by offering two subsections, one exploring how professional networks and connections are linked through discourse to career progression, and one examining how technologies are viewed as unable to substitute for physical presence in collaboration and meetings. This first section serves as a basis for the primary focus of our analysis in the following section, that is, the implications for gender when academic mobility is 'essentialised'. The second section thus first examines how heteronormative discourses disrupt and fragment the opportunities female academics have to engage in 'essential' academic mobility, and then turns to the ways these discourses are challenged and resisted. 


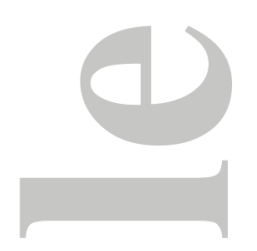

'Essentialising' travel - mobility and the modern academic

Contacts, networks and career progression

I think it's absolutely essential if you're going to have a serious career professionally, which means having connections. Although I've gotten tired of it at times; I'm not always up for it. And, I don't always like feel like socialising and often I don't when I go to conferences but it's still important to go and make those connections and be seen and give those presentations. It's the way that you establish those contacts to work with other people in the profession; to be invited to go places, to be invited to contribute to books and journals and so on, and the way that you establish those professional connections. (\#12/Hum/M/S)

Throughout the above extract the 'essentialising' of academic mobility is functioning in the foreground of the participant's account. From the offset, the binary between the explicit 'serious career professional' and the implicit 'other' (the unserious, unprofessional, academic) is presented with the 'serious' academic clearly anchored on tropes of connections and networks, with the 'other' remaining absent. To further support and reinforce this position the participant offers a reflexive account in which this type of mobility is not desirable/fun as is often the case for leisure travel (Gram, 2005), with there 'often' being times when the participant does not want to 'socialise' or 'go to conferences'. Such a reflexive account enables the position of the 'serious academic' to function through the participant's rhetoric in an implicit fashion through something akin to the 'protestant work ethic' (Mudrack, 1992), in 
which taking one's work/job seriously and committing to the sacrifice and strain of the role is central to notions of 'professionalism' (Morrow \& Goetz Jr, 1988). Expressed differently, justification for academic mobility is positioned in opposition to the fun and frolics associated with leisure travel (Crick, 1989) and thus offered up as something essential to career progression whilst vehemently distancing itself from 'a perk of the job'.

The 'essentialising' of academic travel through professional networks and connections is succinctly captured in the following extract in which the participant likens non-attendance at academic conferences to 'vanishing':

I think basically, networking is just having a physical profile, is really important if you vanish. I have found that. I mean, even from not going to many overseas conferences, you can just vanish from people's minds, really; and it's kind of important to keep networking and keep being involved. (\#27/HS/F/J)

Here a reality is being presented in which there is something unique or special about the 'physicality' of interaction (cf. Strengers, 2015; further elaborated in the following section) to ensure one's professional presence is felt in networks and circles. This supports Leemann's (2010) warning that academics who are not involved in building and maintaining social capital, such as by networking at conferences, are in danger of becoming marginalised.

To expand on the understanding of the need to be known among academic networks attention now turns to a succession of extracts that focus on the direct link between the individual academic and the academic reviewing community (e.g. journal editors, research grant reviewers, journal reviewers). This can be understood as a representation of something akin to tropes of 'an old boys network' in which favourable decisions and resource allocation circulate amongst specific, often gendered, groups (McDonald, 2011). As the following participant comments: 
It's very important for younger people to travel if they have the opportunity to do so. Making networks, contacting, getting themselves in front of editorial boards. It's a bit

of a closed shop and you need access in order, and familiarity, you need to know the Editorial Board in order to be able to have some informal contact with them. $(\# 7 / \mathrm{Com} / \mathrm{M} / \mathrm{S})$

Here there is an explicit recognition of the need to interact on a personal level with those that make decisions on research opportunities (e.g. journal article acceptance; research grant success), wherein academic mobility becomes a strategy for networking with 'influential members of the professional community' (Høyer \& Naess, 2001, 463). Such an understanding further reinforces the 'essential' notion of academic mobility and supports multiple studies which observe that international mobility has become an intrinsic part of an academic career (e.g. Fontes et al.'s, 2013; Glover et al., 2017).

\section{Technology isn't enough}

As noted above, the 'physicality' of the interactions was alluded to as something important in the ways in which academic networks are formed and academic mobility positioned as essential. There have been a plethora of technological advances (e.g. FaceTime, Skype, Video Conferencing) in recent years that have seen a shift in how academics do research (Hanna \& Mwale, 2017). Is this shift in interaction not affecting the ways in which networks are formed and relationships maintained/managed?

From our data it would appear that the discursive positioning of physical interaction on the one hand, and virtual reality on the other, facilitated a situation in which the need for academic 
mobility was reinforced through the need for 'real' and 'personal' interactions that can only happen through 'real' contact. As the following participant comments:

It's simple; if you collaborate with someone you kind of have to have an element of trust which you don't get from a Skype conversation. You need to understand the person quite well to understand that at certain times of the year you want the paper; they're working on a paper and it's going very slow but you know they're under a lot of pressure so you don't hassle. You kind of need to know the people properly and I think if you don't do that it's not much fun for anyone and you wonder why you would bother doing it. So I think it is imperative. (\#18/Sci/M/S)

In this extract personal contact is conflated with trust and understanding to offer up a position in which virtual interactions (via Skype in this instance) do not offer the same level of understanding and appreciation for the collaborating colleague. Personal circumstances (e.g. pressure, stress) are positioned as elements of a relationship that cannot be expressed and appreciated in the same way if the relationship between the individuals is not formulated in a physical space. Such an understanding of physical interactions and relationships as 'real', and virtual relationships as potentially problematic, helps to facilitate the rationale for academic mobility through the construction of something akin to an 'uncomfortable affective atmosphere' in which senses cannot be shared and technology is at the foreground of experience as opposed to something that 'sink[s] into the background' (Adams-Hutcheson \& Longhurst, 2017). In a similar light, the following participant comments on the importance of 'turning up':

So I think the physical being turning up at the meetings is massive for recognition. Perhaps if they don't know who you are I think they'll tend to ignore them and look at 
the papers for the people that they know and I think that's just human nature. (\#28/HS/M/S)

In this extract the physical aspect of human interaction is 'naturalised' through reference to 'human nature' to help uphold the assertion that there is no substitute for personal, face-to-face interaction.

\section{Gender implications under essentialised academic mobility}

The brief analysis above sought not to give a full account of all references in our data in which academic mobility is essential. Rather, we aimed to give the reader an understanding of the discursive formulation of academic mobility as essential. The purpose of this was to provide a precursor for our primary research interest; namely what are the implications for gender when academic mobility is 'essentialised'? What follows in this section is split into two parts: the first explores the ways in which heteronormative discourses disrupt and fragment the opportunities female academics have to engage in 'essential' academic mobility; the second explores the ways in which such heteronormative discourses are challenged and rebuffed by male academics, highlighting the potentially problematic understanding of academic mobility for female and male academics with childcare responsibilities.

'It's a Man's Man's Man's world' (James Brown, 1966)

Well, personally it [recent work travel] was pretty much a negative. Of course it's nice to catch up with colleagues but I have two children and it's a drag leaving them for so long; it was really quite difficult. I hate combining professional and personal travel. I've had to do that, especially when my children were younger and it's just awful feeling 
torn. It's much better to have a 'clean thing' where you show up at a conference then all I do is work the entire time because this is your time away from your family and they're paying a price for you being gone and so you try to be as efficient as possible.

Interviewer: You have combined, taken the kids with you previously but you try not to do that now?

When I was breastfeeding. Yeah, oh it's a nightmare breastfeeding and going to conferences, aaagh! (\#13/Hum/F/S)

Throughout the above extract an alternative construction of academic mobility to that previously documented in this article is present. Here academic mobility is presented as an affectively and emotionally disturbing element to an academic career in which this participant expresses the 'negative' 'drag' 'hate' 'difficult[y]' of academic mobility which resulted in 'feeling torn' between her two children and 'time away from your family', and her professional responsibilities/identity. What we see here then is the same 'essentialising' understanding of academic mobility circulating within this participant's understanding of her career, whilst at the same time the heteronormative gender role of the 'caregiving female' (Eriksson, Sandberg \& Hellström, 2013) functions to entrap this individual in a situation exemplified by the conflicting nature of the two discourses. The academic subjectivity and the subjectivity of the 'mother' are thus incompatible, resulting in a 'way of being' (Heyes, 2007; Rose, 1989) for the participant that is fraught with conflict and distress.

Whilst the above situation can be understood at the purely discursive level in which two conflicting discourses are at play, resulting in the facilitation of broader male academic career progression and inhibited female academic career progression as has been argued elsewhere (Weyer, 2007), in the final sentence we also see an utterance referring to what can be understood as the 'extra-discursive' (Sims-Schouten, Riley \& Willig 2007). In this 
understanding, the 'extra-discursive' can be defined as a range of factors (e.g. parent's/child's health, material/embodied conditions, work/childcare policy) that are "understood as producing a context in which certain discursive constructions are more easily enabled or disenabled than are alternative constructions" (Sims-Schouten et al., 2007, 103). The extradiscursive practice of 'breastfeeding' is mobilized in this extract to offer up the clear physical/biological implications of being a female versus male parent and academic. Whilst we are not suggesting here that male and female academics cannot equally share childcare in terms of time and effort, breastfeeding as a practice is not simply discursively positioned, rather it is a physical/biological practice that cannot be undertaken by both females and males. Such an understanding of breast feeding and being a 'good mother' has been argued to function through the 'Breast is best' rhetoric (Murphy, 1999) and further compounds feelings of failure and distress.

In a similar light the following participant offers an account in which being a mother is in conflict with her academic mobility and academic 'profile'. Once again, we see the emotional drain and affective distress of being a mother and having to travel for academic reputation/progression:

I don't think I travel as much as I should, to maintain a good overseas profile; and I think that's just circumstantial, it's just the logistical difficulties. And I suppose, as well for me; I mean, my daughter got very, very sick last year, and very quickly; and so that has added to my nervousness about leaving her. I don't really travel as much as I probably should. (\#27/HS/F/J)

In our data, gender also played a role in broader understandings of intimate relationships. As the following participant comments: 
I don't travel a lot for a start because my husband does and I don't like us both being away for a lot. So most recently I went to Korea for a conference, to South Korea. That's the only thing I've done this year actually. (\#20/Sci/F/S)

Central to this account, a heteronormative discourse (Gunn, 2009) functions beyond that of the 'caring mother' explored above. Here the subject position of the female academic is constructed in a more passive manner than the male academic counterpart plays out in terms of husband-wife relationships, something akin to a psycho-discursive masculinity (Wetherell \& Edley, 1999). The active husband 'does' travel a lot and this is understood as the primary driver for the female participant not to as she does not 'like us both being away for a lot'. Taken in relation to the above understandings of academic mobility as an 'essential' criteria to career progression we see here hegemonic masculinity enabling the male academic and entrapping the female academic.

In a similar light, the following participant reflects on the career progression of her male counterpart:

My colleague who should have probably been teaching that 300 level paper has been to about three international conferences. But he's married with no kids. His wife doesn't live in New Zealand. So he's a kind of free agent to move around whenever he likes. But I choose to do what I do right now because I think I need to be at home more. $(\# 2 / \mathrm{Com} / \mathrm{F} / \mathrm{J})$

Here we see the juxtaposition between the academically passive 'female' and the academically active 'male'. Whilst passivity and lack of choice are not explicit in the voice of the participant, indeed they are actively challenged in the final sentence in her decision to "choose to do what I do right now because I think I need to be at home more'. However, drawing on Nicholas Rose's (1989) critical understanding of 'choice' as a discursive resource that offers the illusion 
of agency to entrap individuals through more subtle understanding of what is 'right' and 'wrong', the practice of teaching is positioned as the object picked up by those with less of a research profile (facilitated/inhibited purely by academic mobility). Thus whilst the participant states her agency in terms of choice, reference to her colleagues' freedom, her account of her career choices (i.e. picking up the teaching rather than researching), and her reference to the feeling that she 'need[s]', as opposed to 'wants' to be around the home, we can understand this extract as an example of a more subtle outcome of the hegemonic discourse highlighted throughout this section with reference to 'choice' potentially functioning in an illusionary manner.

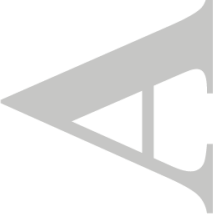

Pockets of resistance to heteronormative and hegemonic ideals

Having seen the ways in which individualised understandings of career profile and progression function through notions of physical presence at international conferences, and the ways in which heteronormative and hegemonic discourses inhibit and entrap female academics in the context of academic mobility, this final section highlights moments of resistance to heteronormative and hegemonic ideals. Whilst accounts in which female academics were passive in their career agency were the most prominent, there were accounts where males resisted their position as dominant career-driven individuals to highlight how affective relationships and caring responsibilities to their families were present. As the following participant comments:

When I was travelling most my children were young and I found that incredibly stressful. Especially when you went on quite long trips. The other thing was when I was travelling I felt that once I travelled for more than two weeks I started to have a huge disconnect with my children. Because, I had no problem envisaging my wife, she was 
absolutely fixed in stone or whatever. But I couldn't remember my children. When your kids are young, they change so much in three weeks so I knew the person I left was going to be a completely different person when I came back. That was quite scary and strange. So, travel I think can be quite stressful when you've got a young family. (\#24/HS/M/S)

Here the well-documented pressure on the early career researcher (Laudel \& Gläser, 2008) is at the forefront of the account. As Schiller and Diez $(2012,1322)$ argue, 'spatial mobility is closely connected with career mobility, especially during the early stages of a career'. It was when this male academic was at the early stages of his career, when his children were young, that he felt the pressure to engage in the most travel. Such a situation is understandable given the rhetoric explored earlier surrounding the need to establish an academic profile and series of networks. However, far from understanding his experiences through a hegemonic discourse in which gender roles would facilitate academic mobility, the participant reflects on his situation though notions of stress and distress. Far from embodying the position of the 'dominant male', this participant recounts the emotional conflict of the work-family balance (Judge, Ilies \& Scott, 2006) due to academic mobility, and the strain this placed on his relationships with his children. Such understandings of work mobility have been found elsewhere (Cohen et al., 2017) and offer up a situation in which the pressure of mobility for career progression results in 'a huge disconnect with my children'. Missing out on seeing his children growing up is positioned as a direct result of the pressure to be a good 'mobile' academic. Such a position has negative consequences for family relationships and the individual's wellbeing, as has been demonstrated in-depth elsewhere (Cohen \& Gössling, 2015).

This juxtaposition between being a 'good academic' versus being a 'good father' is further elaborated in the following extract in which attempts to restrict academic mobility, and the 
durations of the time away, are offered up as a potential mitigation strategy to facilitate relationships with his children, whilst explicit reference to the need for academic mobility is also at play:

We now have two young children so travel is much less flexible hence I go away as shorter time as possible but I still believe it's a really important part of my career so I don't give it up completely. (\#28/HS/M/S)

Indeed, the duration of the trip appears to be one of the most prominent factors in attempting to overcome the binary between academic progression and being a good father and husband.

Not only is the position of the 'male' disrupted through understandings in which 'missing out' on their children growing up is placed as a central concern, but we also see a more affective series of understandings, similar to those offered above by the female academics, in which guilt and stress are central to their accounts. This is not unlike Heyes' (2007) notion of disrupting gender discourses and consequent subject positions through resistive practices. As the following comment:

(1)

When I went to Perth it was just a week which is fine, but when I went to the UK it was two weeks away from the kids so that's really hard. It's hard also because we're relatively new to New Zealand; we don't have a family support network so if I'm away and my wife feels unwell then it's really hard. (\#3/Com/M/J)

It's also hard for my wife because she's left looking after the three kids while I'm flying around. I don't like going away for long periods either, so I guess that's a barrier and a compromise to travel. (\#31/HS/M/J)

In these final extracts there are explicit references to the emotional distress experienced from not seeing young children, and reflections on the guilt felt by placing the parental 
responsibilities solely on the mother during periods of academic mobility, potentially exacerbated by the lack of 'family support network[s]'. Thus the very notion of the 'dominant' and less emotional male may be challenged and disrupted.

\section{Conclusions}

This paper's focus on discourse has contributed a new theoretical understanding of how discourse works to constitute the essentialisation of academic mobility, and the uneven gendered practices associated with it. We show how mobility is discursively constructed as 'essential' to an academic career, leading to differing realities of gender, obligations of care and parenting in relation to academic mobility practices. What is crucial overall here is that discourse is doing the work: there is often no real need to travel at a pragmatic level, but rather that 'need' functions through discourse that enables and disables particular actions and consequences. Our findings have shown how the need for frequent academic mobility is justified despite advances in virtual communication technologies. We gave a strong account of how dominant discourses constructing the modern 'academic' and gender render parenting and a 'good' academic career as incompatible, particularly for female academics. The tension between these hegemonic and heteronormative discourses - coupled with, and circulating through the construction of the 'good mother' as one that is always physically present - disrupts and fragments opportunities for female academics to engage in academic mobility. Our accounts have also highlighted, however, moments in which these dominant discourses are challenged and resisted, wherein fathers articulate emotional strain associated with academic mobility. Both female and male academics reflect on notions of stress and guilt that arise from the competing obligations of family and academic mobility. 
These findings may challenge the dominant discourse associated with 'less emotional males' and traditional gender roles. The paper thus furthermore contributes to research on gender that avoids the perpetuation of discursive binaries by resisting heteronormative discourses, in addition to its primary theoretical contribution in showing the crucial role of discourse in constituting the essentialisation of academic mobility, and the implications for gendered practices. The paper's contribution also lies in having given voice to gender inequities in academic mobility from a southern hemisphere context, in which distance to the historical academic hubs of Europe and the USA is at its most stretched. As most studies of gender aspects in academic mobility have been contextually-focused in Europe (Jöns, 2011; 2017; Lassen, 2009; Leemann, 2010; Santos, 2015), it has been important to consider gender within how knowledge workers in other regions of the world negotiate mobility demands, such as in the case of New Zealand's physical remoteness and the priority that its universities place on mobility in the hope of remaining competitive internationally.

This paper shares a limitation with Storme et al. (2017), in that the study sample was drawn from a university where part of the project team was working, as this enabled access. Though its geographical focus in New Zealand means its findings are contextually-bound, its insights are likely to have resonance for academics and other knowledge workers more widely, especially when considering Baruch and Hall's $(2004,257)$ assertion that 'the gap between the academic career model and the corporate model has been decreasing'. As universities are 'gradually normalizing hypermobility as central to university life' (Glover et al., 2017, 9), future research is necessary to understand the gender implications of these processes in other ways, and in particular how these institutional expectations are challenged and resisted, such as by both female and male academics who decide to reduce or restrict work-related mobility. 


\section{References}

Ackers, L. (2008). Internationalisation, mobility and metrics: A new form of indirect discrimination? Minerva, 46: 411-435.

Adams-Hutcheson, G. \& Longhurst, R. (2017). 'At least in person there would have been a cup of tea': interviewing via Skype. Area, 49(2): 148-155.

Aguilera, A. (2008). Business travel and mobile workers. Transportation Research Part A, 42: 1109-1116.

Bailyn, L. (2003). Academic careers and gender equity: Lessons learned from MIT. Gender, Work and Organization, 10(2), 137-153.

Baruch, Y. \& Hall, D.T. (2004). The academic career: A model for future careers in other sectors? Journal of Vocational Behaviour, 64, 241-262.

Bhavnani, K. \& Phoenix, A. (1994). Shifting identities shifting racisms: a feminism \& psychology reader. London: Sage.

Bergström Casinowsky, G. (2013). Working life on the move, domestic life at standstill? Workrelated travel and responsibility for home and family. Gender, Work and Organization, 20(3), 311-326.

Bohan, J. S. (1993). Regarding gender: Essentialism, constructionism, and feminist psychology. Psychology of women quarterly, 17(1), 5-21.

Clarke, J., \& Saraga, E. (2003). Embodying the social: Construction of difference. London: Routledge.

Cohen, S.A. \& Gössling, S. (2015). A darker side of hypermobility. Environment and Planning A, 47(8): 166-1679.

Cohen, S.A., Hanna, P. \& Gössling, S. (2017). The dark side of business travel: A media comments analysis. Transportation Research Part D, doi: 10.1016/j.trd.2017.01.004

Crick, M. (1989). Representations of international tourism in the social sciences: Sun, sex, sights, savings, and servility. Annual Review of Anthropology, 18(1): 307-344.

Edley, N and Wetherell, M (2008). Discursive psychology and the study of gender: a contested space. In: Harrington, K; Litosseliti, L; Saunston, H and Sunderland, J eds. Gender and Language Research Methodologies. Basingstoke, UK: Palgrave Macmillan, pp. 161-173.

Eriksson, H., Sandberg, J. \& Hellström, I. (2013). Experiences of long-term home care as an informal caregiver to a spouse: gendered meanings in everyday life for female carers. International Journal of Older People Nursing, 8(2): 159-165.

Fontes, M., Videira, P. \& Calapez, T. (2013). The impact of long-term scientific mobility on the creation of persistent knowledge networks. Mobilities, 8(3): 440-465.

Glover, A., Strengers, Y. \& Lewis, T. (2017). The unsustainability of academic aeromobility in Australian universities. Sustainability: Science, Practice and Policy, 13(1): 1-12.

Gram, M. (2005). Family holidays. A qualitative analysis of family holiday experiences. Scandinavian Journal of Hospitality and Tourism, 5(1): 2-22. 
Gunn, A.C. (2009). 'But who are the parents?' Examining heteronormative discourses in New Zealand government early childhood reports and policy. Early Childhood Folio, 13: 27-32.

Hanna, P. (2013). Reconceptualizing subjectivity in critical social psychology: Turning to Foucault. Theory \& Psychology, 23(5), 657-674.

Hanna, P. (2014). Foucauldian discourse analysis in psychology: Reflecting on a hybrid reading of Foucault when researching "ethical subjects". Qualitative Research in Psychology, 11(2): 142-159.

Hanna, P. \& Mwale, S. (2017). I'm not with you, yet I am... virtual face-to-face interviews. In Collecting Qualitative Data: a practical guide to textual, media and virtual techniques, edited by V. Braun, V. Clarke \& D. Gray, 256-272. Cambridge: Cambridge University Press.

Heyes, C.J. (2006). Foucault goes to weight watchers. Hypatia, 21(2), 126-149.

Heyes, C.J. (2007). Self-Transformations: Foucault, ethics, and normalized bodies. Oxford: Oxford University Press.

Higham, J.E.S., Hopkins, D. \& Orchiston, C. (2019). The work-sociology of academic aeromobility at remote institutions: Networks, co-presence and proximity. Mobilities, DOI: 10.1080/17450101.2019.1589727

Hopkins, D., Higham, J., Tapp, S. \& Duncan, T. (2016). Academic mobility in the Anthropocene era: a comparative study of university policy at three New Zealand institutions. Journal of Sustainable Tourism, 24(3): 376-397.

Hopkins, D., Higham, J.E.S., Orchiston, C., \& Duncan, T. (2019). The practice of academic mobilities: bodies, networks and institutional rhythms, The Geographical Journal. DOI: 10.1111/geoj.12301

Høyer, K.G. \& Naess, P. (2001). Conference tourism: A problem for the environment as well as for research? Journal of Sustainable Tourism, 9(6): 451-470.

Jöns, H. (2011). Transnational academic mobility and gender. Globalisation, Societies and Education, 9(2), 183-209.

Jöns, H. (2017). Feminizing the university: The mobilities, careers, and contributions of early female academics in the University of Cambridge, 1926-1955. The Professional Geographer, 69(4), 670-682

Jennings, G. (2001). Tourism research. Milton: John Wiley \& Sons.

Judge, T.A., Remus, I. \& Scott, B.A. (2006). Work-family conflict and emotions: Effects at work and at home. Personnel Psychology, 59(4): 779-814.

King, R. (2002). Towards a new map of European migration. International Journal of Population Geography. 8: 89-106.

Lassen, C. (2009). Networking, knowledge organizations and aeromobility. Geografiska Annaler: Series B, Human Geography, 91(3): 229-243. 
Lassen, C., Laugen, B.T. \& Naess, P. (2006). Virtual mobility and organizational reality - a note on the mobility needs in knowledge organisations. Transportation Research Part D, 11, 459-463.

Laudel, G. \& Gläser, J. (2008). From apprentice to colleague: The metamorphosis of early career researchers. Higher Education, 55(3): 387-406.

Leemann, R.J. (2010). Gender inequalities in transnational academic mobility and the ideal type of academic entrepreneur. Discourse: Studies in the Cultural Politics of Education, 31(5): 605-625.

McDonald, S. (2011). What's in the "old boys" network? Accessing social capital in gendered and racialized networks. Social Networks, 33(4): 317-330.

Morrow, P.C. \& Goetz Jr, J.F. (1988). Professionalism as a form of work commitment. Journal of Vocational Behavior, 32(1): 92-111.

Mudrack, P.E. (1992). 'Work' or 'Leisure'? The Protestant work ethic and participation in an employee fitness program. Journal of Organizational Behavior, 13(1): 81-88.

Murphy, E. (1999). 'Breast is best': infant feeding decisions and maternal deviance. Sociology of Health \& Illness, 21(2): 187-208.

Nevins, J. (2014). Academic jet-setting in a time of climate destabilization: Ecological privilege and professional geographic travel. The Professional Geographer, 66(2):

Parker, I. (1992). Discourse dynamics: Critical analysis for social and individual psychology. London: Routledge.

Parker, M. \& Weik, E. (2013). Free spirits? The academic on the aeroplane. Management Learning, 45(2): 167-181.

Potter, J. \& Wetherell, M. (1987). Discourse and Social Psychology: Beyond attitudes and behaviour. London: Sage.

Rose, N. (1989). Governing the Soul. London: Routledge.

Santos, G.G. (2015). Narratives about work and family life among Portuguese academics. Gender, Work \& Organization, 22(1): 1-15.

Saxenian, A. (2005). From brain drain to brain circulation: Transnational communities and regional upgrading in India and China. Studies in Comparative International Development, $40(2), 35-61$.

Schiller, D. \& Diez, J.R. (2012). The impact of academic mobility on the creation of localized intangible assets. Regional Studies, 46(1): 1319-1332.

Sims-Schouten, W., Riley, S.C.E. \& Willig, C. (2007). Critical realism in discourse analysis: A presentation of a systematic method of analysis using women's talk of motherhood, childcare and female employment as an example. Theory \& Psychology, 17(1): 101-124.

Storme, T., Faulconbridge, J.R., Beaverstock, J.V., Derudder, B. \& Witlox, F. (2017). Mobility and professional networks in academia: An exploration of the obligations of presence. Mobilities, 12(3): 405-424. 
Strengers, Y. (2015). Meeting in the global workplace: Air travel, telepresence and the body. Mobilities, 10(4): 592-608.

Urry, J. (2003). Social networks, travel and talk. The British Journal of Sociology. 54(2): 155175 .

Wetherell, M. \& Edley, N. (1999). Negotiating hegemonic masculinity: Imaginary positions and psycho-discursive practices. Feminism \& Psychology, 9(3): 335-356.

Weyer, B. (2007). Twenty years later: explaining the persistence of the glass ceiling for women leaders. Women in Management Review, 22(6): 482-496.

Willig, C. (2001). An Introduction to Qualitative Research in Psychology: Adventures in Theory and Method. Buckingham: Open University Press.

Willig, C. (2008). Discourse Analysis. In Qualitative Psychology: A practical guide to research methods, edited by J Smith. London: Sage.

Willig, C. (2013). Introducing qualitative research in psychology: Maidenhead: McGraw-Hill Education.

Winslow, S. \& Davis, S.N. (2016). Gender inequality across the academic life course, Sociological Compass, 10(5): 404-416.

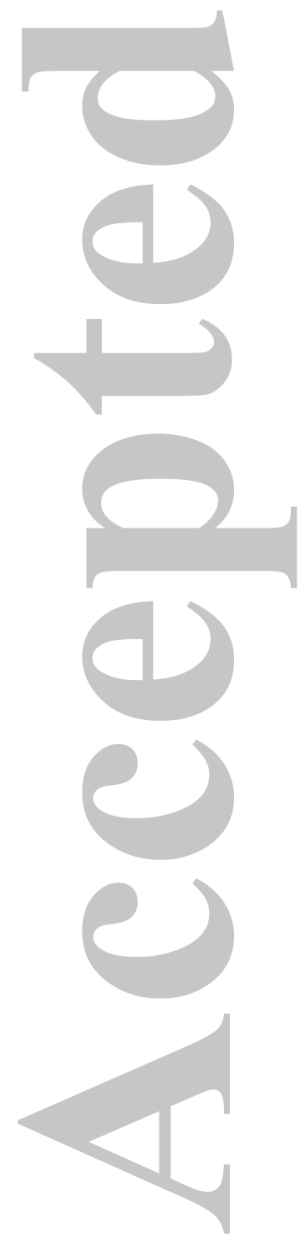


Table 1. Summary of interview participants

\begin{tabular}{|c|c|c|c|c|}
\hline Interview code $\dagger$ & Division & Gender & Academic position & $\begin{array}{l}\text { Interview length } \\
\text { (minutes) }\end{array}$ \\
\hline$\# 1 / \mathrm{Com} / \mathrm{M} / \mathrm{S}$ & Commerce & Male & Associate Professor & 34 \\
\hline \#2/Com/F/J & Commerce & Female & Lecturer & 32 \\
\hline \#3/Com/M/J & Commerce & Male & Senior Lecturer & 34 \\
\hline \#4/Com/F/J & Commerce & Female & Senior Lecturer & 39 \\
\hline$\# 5 / \mathrm{Com} / \mathrm{M} / \mathrm{S}$ & Commerce & Male & Associate Professor & 47 \\
\hline \#6/Com/M/S & Commerce & Male & Associate Professor & 49 \\
\hline \#7/Com/M/S & Commerce & Male & Professor & 59 \\
\hline \#8/Hum/M/S & Humanities & Male & Professor & 54 \\
\hline \#9/Hum/F/S & Humanities & Female & Associate Professor & 43 \\
\hline \#10/Hum/M/J & Humanities & Male & Senior Lecturer & 52 \\
\hline \#11/Hum/M/J & Humanities & Male & Lecturer & 44 \\
\hline \#12/Hum/M/S & Humanities & Male & Professor & 59 \\
\hline \#13/Hum/F/S & Humanities & Female & Associate Professor & 47 \\
\hline$\# 14 / \mathrm{Hum} / \mathrm{M} / \mathrm{S}$ & Humanities & Male & Professor & 41 \\
\hline \#15/Hum/M/S & Humanities & Male & Associate Professor & 36 \\
\hline$\# 16 / \mathrm{Sci} / \mathrm{M} / \mathrm{J}$ & Sciences & Male & Lecturer & 22 \\
\hline \#17/Sci/M/J & Sciences & Male & Postdoctoral Fellow & 50 \\
\hline \#18/Sci/M/S & Sciences & Male & Professor & 54 \\
\hline \#19/Sci/M/J & Sciences & Male & Lecturer & 45 \\
\hline \#20/Sci/F/S & Sciences & Female & Associate Professor & 36 \\
\hline \#21/Sci/F/J & Sciences & Female & Senior Lecturer & 42 \\
\hline \#22/Sci/M/J & Sciences & Male & Lecturer & 36 \\
\hline \#23/Sci/F/S & Sciences & Female & Professor & 47 \\
\hline \#24/HS/M/S & Health Sciences & Male & Professor & 42 \\
\hline \#25/HS/M/S & Health Sciences & Male & Associate Professor & 29 \\
\hline \#26/HS/F/J & Health Sciences & Female & Senior Lecturer & 44 \\
\hline \#27/HS/F/J & Health Sciences & Female & Senior Lecturer & 48 \\
\hline \#28/HS/M/S & Health Sciences & Male & Professor & 42 \\
\hline \#29/HS/F/J & Health Sciences & Female & Senior Research Fellow & 33 \\
\hline \#30/HS/M/J & Health Sciences & Male & Senior Research Fellow & 35 \\
\hline \#31/HS/M/J & Health Sciences & Male & Lecturer & 42 \\
\hline
\end{tabular}

$\uparrow$ The University of Otago departments are organized into four divisions. Com=Commerce, Hum=Humanities, Sci=Sciences, HS=Health Sciences; S denotes senior academic positions: Professor and Associate Professor; J denotes junior academic positions: Senior Lecturer, Lecturer, Senior Research Fellow and Postdoctoral Fellow. 